\title{
Estimation of breeding value for bodyweight of grasscutters
}

Udeh, I.



Abstract
Department of Animal Science, Delta State University,

Asaba Campus, Asaba, Nigeria

Corresponding author:drudeh2005@yahoo.com

Animal breeders are interested in the genetic worth or total genetic merit of an animal for a given trait. The value of an animal in a breeding program for a particular trait is called the breeding value. The aim of this study was to predict the breeding values for bodyweight of grasscutters at 4, 6 and 8 months of age using univariate animal model. Four families of grasscutters with five grasscutters per family were used for the study. Families 3 and 4 had higher bodyweight at 4 and 6 months compared with families 1 and 2. Family 4 had the highest bodyweight at 8 month and family 2 had the least. The estimated breeding values $(E B V)$ for bodyweight of grasscutters ranged from $-0.06 \mathrm{~kg}$ to $0.45 \mathrm{~kg}$ at 4 month, $-0.05 \mathrm{~kg}$ to $0.45 \mathrm{~kg}$ at 6 month and $-0.04 \mathrm{~kg}$ to $0.55 \mathrm{~kg}$ at 8 month. The reliability of the $E B V(\%)$ ranged from 51.00 to $62.50,22.25$ to 43.81 and 25.84 to 49.00 at 4,6 and 8 months of age respectively. This implies that the correlations between estimated breeding value and true genetic merit were medium to high in magnitude. The reliability of the EBV could be improved further through collecting more phenotypic information on the animal and its relatives and by improving the heritability of the trait.

Keywords: Animal model, estimated breeding value, reliability

\section{L'Estimation de la valeur de reproduction pour le poids corporel des coupe-herbes}

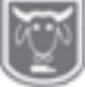

\section{Résumé}

Les éleveurs s'intéressent à la valeur génétique ou au mérite génétique total d'un animal pour un trait donné. La valeur d'un animal dans un programme d'élevage pour un trait particulier est appelée valeur de reproduction. Le but de cette étude était de prédire les valeurs de reproduction du poids corporel des coupe-herbes à l'âge de 4, 6 et 8 mois à l'aide d'un modèle animal univarié. Quatre familles de coupe-herbes avec cinq coupes-herbes par famille ont été utilisées pour l'étude. Les familles 3 et 4 avaient un poids corporel plus élevé à 4 et 6 mois comparativement aux familles 1 et 2. Famille 4 avait le poids corporel le plus élevé à 8 mois et la famille 2 avait le moins. Les valeurs de reproduction estimées (le 'EBV') pour le poids corporel des coupe-herbes allaient de -0,06 kg à 0,45 kg à 4 mois, -0,05 $\mathrm{kg}$ à $0,45 \mathrm{~kg}$ à 6 mois et -0,04 kgà 0,55 kgà 8 mois. La fiabilité de l'EBV (\%) 51,00 à 62,50, 22,25 à 43,81 et 25,84à 49,00 à 4, 6 et 8 mois respectivement. Cela implique que les corrélations entre la valeur de reproduction estimée et le véritable mérite génétique étaient de taille moyenne à élevée. La fiabilité de l'EBV pourrait être encore améliorée en recueillant plus d'informations phénotypique sur l'animal et ses parents et en améliorant l'hérabilité du trait.

Mots-clés: Modèle animal, valeur de reproduction estimée, fiabilité

\section{Introduction}

Grasscutters are fairly large rodent found in West, Central and some parts of East Africa. The animal is hunted in the wild for its meat which is a local delicacy in West and Central
Africa (Udeh and Isiorho, 2016). There have been efforts over the years to domesticate grasscutters in order to augment the protein requirements of West and Central Africa people (Adenyo et al, 


\section{Estimation of breeding value for bodyweight of grasscutters}

2012). Grasscutters have not been subjected to genetic improvement programmes. Many traits of economic importance in grasscutters such as bodyweight, litter size, feed efficiency, etc, need to be genetically improved. Steps to genetic improvement involve definition of breeding objectives and estimation of trait breeding values for candidates available for selection. EBVs are predictions of future offspring performance. Therefore, we need a measure of confidence in an animal EBV. Confidence or the accuracy of EBV is measured by the correlation between predicted breeding value and true breeding value. The higher the accuracy, the more confidence we are in the EBV (Redden, 2012). The accuracy of the EBV is influenced by factors such as the amount of performance information available on the animal and its relative, the heritability of the trait and the size of the group the animal is compared (Redden, 2012). EBVs are available for most livestock species in both individual traits and multiple trait indexes. This information is lacking in the domesticated grasscutter. The objective of this study was to estimate the breeding value for bodyweight in a population of grasscutters in Asaba, Delta State, Nigeria.

\section{Materials and methods The study area}

The study was conducted at the grasscutter unit of Department of Animal Science, Delta State University, Asaba Campus. Asaba is located at latitude $6^{\circ} 11^{\prime}$ North and longitude $6^{0} 45^{\prime}$ East. Asaba has an annual rainfall that range from 1800 t0 $3000 \mathrm{~mm}$. Maximum temperature in the area is from $27.5^{0 \mathrm{c}}$ to $39.9^{0 \mathrm{c}}$ (Federal Ministry of Aviation and Meteorological services).

\section{The experimental animal and their management}

The experimental animals consist of four families of grasscutters with five grasscutters per family. The pedigree records show that the four families of grasscutters were sired by 4 males and dam by 4 females. The housing and feeding management of the grasscutter families were described by Udeh and Okonta (2013), Udeh and Isiorho (2016) and Udeh (2020).

\section{The data}

The pedigree file consists of animal identity, sire and dam. There were 28 animals in the pedigree. The first 8 animals in the pedigree were parents and they did not have records. The last 20 animals in the pedigree were progenies of the parents and had records. The data file consists of records of bodyweight arranged according to families at 4, 6 and 8 months of age. There were four families and each family has five animals with records. Each family has 4 females and 1 male. Preliminary analysis testing the fixed effects of family and sex with $\operatorname{lm}()$ function of R shows that sex and its interaction with family was not significant $(\mathrm{p}>0.05)$. Therefore, sex was not added to the mixed model equation.

\section{The model}

A univariate animal model was used for the analysis of the data. In matrix notation, the mixed model is written as: $\mathrm{Y}=\mathrm{Xb}+\mathrm{Za}+\mathrm{e}$, where $\mathrm{Y}=$ vector of bodyweight, $\mathrm{b}=$ solution vector for fixed effect of family, $\mathrm{a}=$ solution vector for random additive genetic effect, $X$ and $Z=$ incidence matrices which relate bodyweight to fixed and random effect respectively and $\mathrm{e}=$ residual. The expectation (E) of the random variables were $\mathrm{E}(\mathrm{Y})=\mathrm{Xb}, \mathrm{E}(\mathrm{a})=\mathrm{E}(\mathrm{e})=0$. It was assumed that the residual variance was independently distributed with variance $\sigma^{2}$ e. Therefore, variance of $\mathrm{e}=1 \sigma^{2} \mathrm{e}=\mathrm{R}$; variance $a=A \sigma^{2} a=G$ where $I$ and $A$ were identity and numerator relationship matrix respectively. Variance $\mathrm{Y}=\mathrm{ZGZ}+\mathrm{R}$. The following mixed model equations were solved to obtain the best linear unbiased estimator of fixed effect (b) and the best linear unbiased predictions of breeding value (a). 


$$
\left[\begin{array}{l}
b \\
a
\end{array}\right]=\left[\begin{array}{cc}
x^{\prime} X & x^{\prime} Z \\
Z^{\prime} X & Z^{\prime} Z+A^{-1} a
\end{array}\right]^{\prime}\left[\begin{array}{l}
X^{\prime} Y \\
Z^{\prime} y
\end{array}\right]
$$

Where $\alpha=\sigma^{2} \mathrm{e} / \sigma^{2} \mathrm{a}$ or $\left(1-\mathrm{h}^{2}\right) / \mathrm{h}^{2}$ (Mrode, 2005). A prior value for $\sigma^{2} a, \sigma^{2}$, and $h^{2}$ was assumed to be $0.03,0.03$ and 0.57 at 4 month of age and $0.03,0.03$, and 0.50 at 6 and 8 months respectively. The prior values were calculated from similar data using MCMCglmm R (Hadfield, 2014). The standard error of prediction (SEP) of a predicted breeding value was calculated as the square root of the product of the diagonal of the inverse of left hand side (LHS) of the mixed model equation (MME) times the estimate of the residual variance (Schaeffer, 2011). The reliability (REL) of EBV which is another measure of the accuracy of the estimate is calculated as follows: $R_{E L}=\left(a_{i j} \sigma^{2} a-c_{i i} \sigma^{2} e\right) / \sigma^{2} a$ where $a_{i i}$ is the diagonal of A matrix for animal $\mathrm{i}, \mathrm{c}_{\mathrm{ii}}$ is the diagonal of the inverse of the LHS for animal $i, \sigma^{2}$ a is the additive genetic variance and $\sigma^{2} e$ is residual variance. The mixed model equation was solved using $\mathrm{R}$ version 64.3.1.3 (R core team, 2015).

\section{Results and discussion}

Table 1 presents the solutions of fixed effect of family on bodyweight of grasscutters. The solutions of fixed effect indicate that families 3 and 4 had numerically higher bodyweight at 4 and 6 months of age compared to families 1 and 2 . Family 4 had the highest bodyweight at 8 months of age followed by families 3, 1 and 2 in that order. The variability in the average bodyweight of families at each age period suggests genotypic difference among families. The best linear unbiased predictions of body weight of grasscutters are presented in Table 2 .

Table 1: Solutions of fixed effect of family on body weight of grasscutters at 4, 6 and 8 months of age (kg)

\begin{tabular}{llllllllll}
\hline Family & BWT4 & SEP & REL & BWT6 & SEP & REL & BWT8 & SEP & REL \\
\hline 1 & 0.38 & 0.002 & 67.50 & 0.61 & 0.002 & 46.67 & 1.12 & 0.002 & 51.09 \\
2 & 0.28 & 0.002 & 75.00 & 0.51 & 0.002 & 57.81 & 1.02 & 0.002 & 62.47 \\
3 & 0.45 & 0.002 & 75.00 & 0.66 & 0.002 & 57.81 & 1.13 & 0.002 & 62.47 \\
4 & 0.42 & 0.002 & 67.50 & 0.67 & 0.002 & 46.67 & 1.27 & 0.002 & 51.09 \\
\hline
\end{tabular}

Note: BWT4, BWT6 and BWT8= Body weight at 4, 6 and 8 months respectively , REL= Reliability $(\%)$, $\mathrm{SEP}=$ Standard error of prediction

Among the animals that do not have records (animals 1-8), animals 1, 2, 5, 6 had positive EBV at 4 and 6 months while animals 1, 2, 5, 6 and 7 had positive EBV at 8 month of age. Under this group, animal 6 had the highest EBV at 4, 6 and 8 months of age, followed by animal 2. Majority of the animals with records (animals $9-28$ ) had positive EBV at 4 and 6 months of age while all the animals with records had positive EBV at 8 month of age. Animal 19 had the highest EBV at 4, 6 and 8 months of age, followed by animal 27 at 4 and 6 months and animal 23 at 8 month of age. The EBVs of some of the animals were quite high which implies high transmitting ability to their expected progenies (Udeh et al, 2020). Animal 19 which had the highest EBV is expected to produce progenies whose genetic potential is $0.23 \mathrm{~kg}, 0.22 \mathrm{~kg}$ and $0.28 \mathrm{~kg}$ heavier at 4,6 and 8 months respectively compared to an animal with EBV at 0 . The SEP was almost the same for all estimates $(0.002-0.003)$. The reliability of the EBV for all animals ranged from $51.00 \%-65.32 \%$ at 4 month, $22.25 \%-43.81 \%$ at 6 month and $25.84 \%$ $49.00 \%$ at 8 month of age. Publication of official EBV in cattle is allowed for a minimum reliability of $50 \%$ (Amandine, 2015). The reliability of the EBV is the correlation between the EBV and true breeding value for the trait of interest. It is a 


\section{Estimation of breeding value for bodyweight of grasscutters}

Table 2: Best linear unbiased predictions of breeding values of body weight of grasscutters at 4, 6 and 8 months of age (kg)

\begin{tabular}{|c|c|c|c|c|c|c|c|c|c|}
\hline Animal & BWT4 & SEP & REL & BWT6 & SEP & REL & BWT8 & SEP & REL \\
\hline 1 & 0.01 & 0.002 & 51.00 & 0.00 & 0.003 & 22.25 & 0.00 & 0.003 & 25.84 \\
\hline 2 & 0.06 & 0.002 & 65.25 & 0.05 & 0.002 & 43.81 & 0.06 & 0.002 & 49.00 \\
\hline 3 & -0.06 & 0.002 & 62.50 & -0.04 & 0.002 & 39.62 & -0.03 & 0.002 & 44.21 \\
\hline 4 & -0.04 & 0.002 & 62.50 & -0.05 & 0.002 & 39.88 & -0.11 & 0.002 & 44.16 \\
\hline 5 & 0.01 & 0.002 & 62.50 & 0.01 & 0.002 & 39.62 & 0.01 & 0.002 & 44.16 \\
\hline 6 & 0.07 & 0.002 & 62.50 & 0.06 & 0.002 & 39.62 & 0.07 & 0.002 & 44.21 \\
\hline 7 & -0.03 & 0.002 & 65.32 & -0.01 & 0.002 & 43.81 & 0.04 & 0.003 & 49.00 \\
\hline 8 & -0.01 & 0.002 & 51.00 & -0.00 & 0.003 & 22.25 & -0.04 & 0.003 & 25.84 \\
\hline 9 & 0.16 & 0.002 & 55.00 & 0.09 & 0.003 & 28.46 & 0.28 & 0.003 & 32.52 \\
\hline 10 & 0.15 & 0.002 & 55.00 & 0.19 & 0.003 & 28.46 & 0.27 & 0.003 & 32.52 \\
\hline 11 & 0.06 & 0.002 & 55.00 & 0.19 & 0.003 & 28.46 & 0.46 & 0.003 & 32.52 \\
\hline 12 & 0.13 & 0.002 & 55.00 & 0.09 & 0.003 & 28.46 & 0.28 & 0.003 & 32.52 \\
\hline 13 & 0.06 & 0.002 & 55.00 & 0.14 & 0.003 & 28.46 & 0.30 & 0.003 & 32.52 \\
\hline 14 & 0.01 & 0.002 & 60.75 & 0.05 & 0.002 & 37.08 & 0.21 & 0.002 & 41.49 \\
\hline 15 & 0.04 & 0.002 & 60.75 & 0.08 & 0.002 & 37.08 & 0.18 & 0.002 & 41.49 \\
\hline 16 & 0.01 & 0.002 & 60.75 & 0.04 & 0.002 & 37.08 & 0.22 & 0.002 & 41.49 \\
\hline 17 & 0.04 & 0.002 & 60.75 & 0.08 & 0.002 & 37.08 & 0.22 & 0.002 & 41.49 \\
\hline 18 & 0.01 & 0.002 & 60.75 & 0.04 & 0.002 & 37.08 & 0.20 & 0.002 & 41.49 \\
\hline 19 & 0.45 & 0.002 & 60.75 & 0.45 & 0.002 & 37.08 & 0.55 & 0.002 & 41.49 \\
\hline 20 & 0.08 & 0.002 & 60.75 & -0.01 & 0.002 & 37.08 & 0.18 & 0.002 & 41.49 \\
\hline 21 & 0.01 & 0.002 & 60.75 & 0.08 & 0.002 & 37.08 & 0.18 & 0.002 & 41.49 \\
\hline 22 & 0.01 & 0.002 & 60.75 & -0.01 & 0.002 & 37.08 & 0.20 & 0.002 & 41.49 \\
\hline 23 & 0.01 & 0.002 & 60.75 & 0.23 & 0.002 & 37.08 & 0.52 & 0.002 & 41.49 \\
\hline 24 & -0.02 & 0.002 & 55.19 & -0.03 & 0.003 & 28.46 & 0.10 & 0.003 & 32.45 \\
\hline 25 & -0.06 & 0.002 & 55.19 & -0.00 & 0.003 & 28.46 & 0.18 & 0.003 & 32.45 \\
\hline 26 & 0.01 & 0.002 & 55.19 & 0.06 & 0.003 & 28.46 & 0.38 & 0.003 & 32.45 \\
\hline 27 & 0.32 & 0.002 & 55.19 & 0.19 & 0.003 & 28.46 & 0.44 & 0.003 & 32.45 \\
\hline 28 & 0.05 & 0.002 & 55.19 & 0.19 & 0.003 & 28.46 & 0.42 & 0.003 & 32.45 \\
\hline
\end{tabular}

Note: BWT4, BWT6 and BWT8 = Body weight at 4, 6 and 8 months respectively, REL= Reliability (\%), $\mathrm{SEP}=$ Standard error of prediction

measure of the amount of information that has contributed to the genetic evaluation and can be used to derive confidence intervals for the estimated breeding value (Harris and Johnson, 1998). The reliability of the estimates could be increased by getting more performance information on the animal itself and on its progenies as well as increasing heritability of the trait.

\section{Conclusion and recommendation}

The estimated breeding value for bodyweight of the grasscutters evaluated range from -0.06 to $0.45 \mathrm{~kg}$ at 4 month, -0.05 to $0.45 \mathrm{~kg}$ at 6 month and -0.04 to $0.55 \mathrm{~kg}$ at 8 month of age respectively. The reliability of the EBV (\%) ranged from 51.00 to 62.50 at 4 month, 22.25 to 43.81 at 6 month and 25.84 to 49.00 at 8 month of age. It was suggested that the correlation between the EBV and true breeding value could be step up by collecting more phenotypic information on the animal and its relatives and by increasing the heritability of the trait.

\section{References}

Adenyo, C., Hayano, A., Inoue, E., Kayang, B. B. and Murayama, $M$. 
I. 2012. Development of microsatellite markers for grasscutters (Thryonomys swinderianus, Rodenta) using next generation sequencing technology. Conservation Genetic Resource Vol. 4 issue 4: $1011-1014$.

Amadine, L. 2015. Genetic evaluation: Methods and definitions. www.jouy.inra.fr/gabi. 1-56

Hadfield, J. 2014. MCMCglmm course notes. MCMCglmm $\mathrm{R}$ package. URL: http://cran.r-project.org/web /package/MCMCglmm/index.html.

Harris, B. and Johnson, D. 1998. Approximate reliability of genetic evaluations under an animal model. J. Dairy Sci. 81:2723-2728.

Mrode, R. A. 2005. Linear Models for the prediction of Animal Breeding values. $2^{\text {nd }}$ Edition. CAB Publishing. $40-41$.

R Core Team 2015. R: A language and environment for statistical computing. $\mathrm{R}$ foundation for statistical computing, Vienna, Austria. URL http: //www.R project .org/

Redden, R. 2012. Understanding sheep estimated breeding value. NDSU extension services AS1621:1-7. https://www.katahdins.org/ w p c ontent/u p 1 o a d s / $2016 / 02 /$ understanding sheepebvs.pdf.
Schaeffer, L. R. 2011. Animal modelsCourse notes (ANSC 6370), ftp://158.208.129.61/suzuki/AM_ 2011.pdf. University of Guelph.

Udeh, I. 2020. Estimation of variance components for body weight of grasscutters (Thryonomys swinderianus) using a repeatability model. Nig. J. Anim. Prod. 47(2): 33-36.

Udeh, I. and Okonta, B. O. 2013. Prediction of body weight from body measurements in grasscutters. Tropical Anim. Health Production 45: 1331-1334.

Udeh, I. and Isiorho, E. 2016. Repeatability of docility in grasscutters (Thryonomy swinderianus). Journal of Natural Science Research 11(6): 92-94.

Udeh, I., Onowhakpor, C. and Sorhue, G. U. 2020. Estimation of genetic parameters and breeding values for body weight and linear body measurements of mixed flock of cattle breeds. Scientific papers: Animal Science and Biotechnologies 53(2): 105-109.

Received: $6^{\text {th }}$ October, 2020 Accepted: $5^{\text {th }}$ February, 2021 